\title{
KONTRIBUSI HUTAN RAKYAT TERHADAP PENDAPATAN PETANI DI DESA BUANA SAKTI KECAMATAN BATANGHARI KABUPATEN LAMPUNG TIMUR
}

\section{(CONTRIBUTION OF PRIVATE FOREST ON FARMERS INCOME IN BUANA SAKTI VILLAGE SUB DISTRICT OF BATANGHARI DISTRICT OF LAMPUNG TIMUR)}

\author{
Lina Nur Aminah, Rommy Qurniati, dan Wahyu Hidayat \\ Jurusan Kehutanan Fakultas Pertanian Universitas Lampung \\ Jl. Pof. Dr. Sumantri Brojonegoro No. 1 Bandar Lampung 35145 \\ E-mail : Linalinarps@ymail.com
}

\begin{abstract}
ABSTRAK
Penelitian ini bertujuan untuk mengetahui besarnya kontribusi pengelolaan hutan rakyat terhadap pendapatan total petani di Desa Buana Sakti Kecamatan Batanghari Kabupaten Lampung Timur. Penelitian dilaksanakan pada bulan Maret-Mei 2012. Responden adalah 40 petani hutan rakyat yang dipilih secara purposive. Data dikumpulkan dengan menggunakan metode pengamatan langsung di lapangan, wawancara, dan studi pustaka. Metode analisis yang digunakan adalah analisis kuantitatif dan kualitatif. Hasil penelitian menunjukkan bahwa luas rata-rata hutan rakyat milik petani sebesar 0,98 ha dikelola dengan pola monokultur,polikultur dan pola agroforestri. Pada pola monokultur petani menanam tanaman akasia (Acacia mangium), pada pola polikultur petani menanam tanaman akasia (Acacia mangium) dan karet (Hevea brassiliensis) sedangkan pada pola agroforestri petani menanam tanaman akasia (Acacia mangium) dan dkombinasikan dengan lebah madu. Kontribusi hutan rakyat terhadap pendapatan petani tergolong tinggi sebesar Rp 17.619 .649 per tahun $(70,54 \%)$ dari rata-rata pendapatan total rumah tangga petani sebesar $\operatorname{Rp} 24.984 .774$ per tahun.
\end{abstract}

Kata kunci : hutan rakyat, kontribusi, pendapatan petani

\begin{abstract}
This study objective is to determine the contribution of private forest management on farmers total income. This study was conducted in March-May 2012 in the Buana Sakti Village, Sub District of Batanghari, District of Lampung Timur. The number of respondent of this study were 40 private forest farmers. Data were collected by direct field observation, interview, and literature review. Data were then analyzed using qualitative and quantitative analysis methods. The results revealed that the average area of private forest owned by farmers were $0,98 \mathrm{ha}$. The private forest were managed by monoculture, polyculture and agroforestry system. In monoculture system the farmers planted Acacia mangium, in polyculture system the farmers planted Acacia mangium and Hevea brasiliensis while in agroforesty system the farmers combine their land with Acacia mangium, with honey enterprises. The results showed that private forest contribute $R p 17.619 .649$ every year $(70,54 \%)$ of the total farmers household income of $R p 24.984 .774$ every year.
\end{abstract}

Key words : contributions, farmers income, private forest 


\section{PENDAHULUAN}

Hutan rakyat merupakan hutan yang dibangun oleh masyarakat pada lahan milik rakyat. Hutan rakyat tetap penting, karena selain secara ekologi dapat mendukung lingkungan (menahan erosi, mengurangi bahaya banjir, perbaikan tata air, dan penyerapan karbon). Hutan rakyat mampu menghasilkan kayu yang mempunyai nilai ekonomi cukup baik karena dapat memberikan tambahan pendapatan bagi masyarakat (Jaffar, 1993 dalam Elmira, 2009). Desa Buana Sakti Kecamatan Batanghari Kabupaten Lampung Timur merupakan salah satu desa yang mengelola lahan hutan rakyat, dengan luas hutan rakyat 137,5 ha (Profil Desa Buana Sakti, 2011). Pengelolaan hutan rakyat di Desa Buana Sakti memberikan banyak manfaat bagi masyarakat, tidak hanya memperoleh manfaat dari hasil hutan kayu, melainkan juga hasil hutan nonkayu, baik untuk menambah pendapatan maupun digunakan untuk memenuhi kebutuhan hidup. Petani umumnya lebih memusatkan pada pendapatan atau faktor ekonominya dika-renakan pendapatan merupakan penentu bagi kelangsungan hidup petani. Untuk itu diperlukan penelitian kontribusi pendapatan yang diperoleh dari pengelolaan hutan rakyat di Desa Buana Sakti Kecamatan Batanghari Kabupaten Lampung Timur.

Tujuan penelitian adalah untuk mengetahui besar kontribusi yang dihasilkan dari pengelolaan hutan rakyat terhadap pendapatan total petani di Desa Buana Sakti. Penelitian ini diharapkan dapat memberikan informasi kepada masyarakat tentang kontribusi hutan rakyat, sehingga dapat membangun kesadaran masyarakat untuk mengoptimalkan pengelolaan hutan rakyat dan mendorong perluasan hutan rakyat dan dapat digunakan sebagai bahan acuan untuk penelitian lebih lanjut yang terkait.

\section{METODE PENELITIAN}

Penelitian ini dilakukan di Desa Buana Sakti Kecamatan Batanghari Kabupaten Lampung Timur. Penelitian dilaksanakan pada bulan Maret-Mei 2012. Adapun alat yang digunakan dalam penelitian ini adalah alat tulis, kamera, kuesioner, dan seperangkat komputer. Obyek dalam penelitian ini adalah rumah tangga petani yang mengelola lahan hutan rakyat. Data yang diambil dalam penelitian ini adalah data primer dan data sekunder. Data primer meliputi data umum rumah tangga dan data potensi ekonomi rumah tangga. Sedangkan data sekunder meliputi data keadaan umum lokasi penelitian, data statistik, identitas penduduk, data kelompok tani dan buku-buku literatur lain. Pengumpulan data primer dilakukan dengan cara pengamatan langsung di lapangan, dan wawancara. Pengumpulan data sekunder dilakukan dengan menggunakan studi pustaka.

Sampel dipilih dengan menggunakan rumus sebagai berikut (Arikunto, 2000):

$$
n=\frac{N}{N\left(e^{2}\right)+1}
$$

$n$ adalah jumlah responden, $\mathrm{N}$ adalah jumlah total kepala keluarga (KK) semua dusun yang menjadi sampel dan $e$ adalah presisi $15 \%$. Jumlah KK yang memiliki lahan hutan rakyat di Desa Buana Sakti adalah 373 KK sehingga responden dalam penelitian ini adalah sebanyak $40 \mathrm{KK}$.

Jumlah responden tiap dusun dihitung secara proporsional. Berdasarkan perhitungan, jumlah sampel yang diperoleh tiap dusun berbeda-beda yaitu Dusun Sidomukti sebanyak 16 orang, Dusun Sidomakmur sebanyak 11 orang, Dusun Sidoluhur sebanyak 7 orang, dan Dusun Sidowaras sebanyak 6 orang. Data yang telah dihitung dimasukan kedalam tabel. Persamaan-persamaan yang digunakan dalam pengolahan data pendapatan adalah sebagai berikut (Hernanto, 1988 dalam Saefudin, 2007): 
Pendapatan dari hutan rakyat

$\mathrm{R}=\mathrm{Pe}-\mathrm{B}$

Keterangan:

$\mathrm{R}=$ Pendapatan petani dari hutan rakyat $(\mathrm{Rp} / \mathrm{Ha} / \mathrm{Tahun})$

$\mathrm{Pe}=$ Penerimaan dari hutan rakyat $(\mathrm{Rp} / \mathrm{Ha} / \mathrm{Tahun})$

$\mathrm{B}=$ Biaya pengelolaan hutan rakyat $(\mathrm{Rp} / \mathrm{Ha} / \mathrm{Tahun})$

Pendapatan dari pertanian

$\mathrm{Pp}=\mathrm{Ppe}-\mathrm{B}$

$\mathrm{Pp}=$ Pendapatan petani dari pertanian $(\mathrm{Rp} / \mathrm{Ha} / \mathrm{Tahun})$

$\mathrm{Ppe}=$ Penerimaan dari pertanian $(\mathrm{Rp} / \mathrm{Ha} / \mathrm{Tahun})$

$\mathrm{B}=$ Biaya pengelolaan pertanian $(\mathrm{Rp} / \mathrm{Ha} /$ Tahun $)$

Pendapatan dari hewan ternak

$\mathrm{Ph}=\mathrm{Pph}-\mathrm{B}$

$\mathrm{Ph}=$ Pendapatan petani dari hewan ternak (Rp/Tahun)

$\mathrm{Pph}=$ Penerimaan petani dari hewan ternak (Rp/Tahun)

$\mathrm{B}=$ Biaya perawatan hewan ternak (Rp/Tahun)

Pendapatan dari pekerjaan lain

$\mathrm{Pn}=\mathrm{Pl}-\mathrm{B}$

$\mathrm{Pn}=$ Pendapatan petani dari pekerjaan lain (Rp/Tahun)

$\mathrm{Pph}=$ Penerimaan petani dari pekerjaan lain ( $\mathrm{Rp} /$ Tahun $)$

$\mathrm{B}=$ Biaya $(\mathrm{Rp} /$ Tahun $)$

Pendapatan total rumah tangga petani:

$\mathrm{Pt}=\mathrm{R}+\mathrm{Pp}+\mathrm{Ph}+\mathrm{Pn}$

Keterangan:

$\mathrm{Pt}=$ Pendapatan total petani hutan rakyat (Rp/Tahun)

$\mathrm{R}=$ Pendapatan dari hutan rakyat $(\mathrm{Rp} / \mathrm{Ha} / \mathrm{Tahun})$

$\mathrm{Pp}=$ Pendapatan dari pertanian (jumlah panen dikalikan harga tiap komoditas pertanian (Rp/Ha/Tahun)

$\mathrm{Ph}=$ Pendapatan dari hewan ternak (Rp/Tahun)

$\mathrm{Pn}=$ Pendapatan dari lainnya (PNS, wiraswasta, buruh dll (Rp/Tahun)

Kontribusi hutan rakyat terhadap rata-rata pendapatan total petani:

$$
\overline{\mathrm{Kr}}=\frac{\overline{\mathrm{R}}}{\overline{\mathrm{pt}}} \times 100 \%
$$

Keterangan:

$\overline{\mathrm{Kr}}=$ Kontribusi hutan rakyat $(\mathrm{Rp} / \mathrm{Ha} / \mathrm{Tahun})$

$\overline{\mathrm{R}}=$ Pendapatan dari hutan rakyat $(\mathrm{Rp} / \mathrm{Ha} / \mathrm{Tahun})$

$\mathrm{Pt}=$ Pendapatan total petani hutan $(\mathrm{Rp} / \mathrm{Ha} / \mathrm{Tahun})$.

Data yang telah diperoleh dianalisis secara deskriptif kualitatif, dan disajikan dalam bentuk tabulasi dan gambar.

\section{HASIL DAN PEMBAHASAN}

Desa Buana Sakti merupakan salah satu desa yang 37\% penduduknya mengelola lahan yang dimiliki manjadi lahan pertanian dan hutan rakyat. Hutan rakyat di Desa Buana Sakti seluas 137,5 ha dengan status kepemilikan lahan milik masyarakat. Petani mengelola lahan 
hutan rakyat dengan sistem monokultur, polikultur dan sistem agroforestri. Luas lahan yang dikelola oleh masing-masing petani hutan rakyat rata-rata 0,98 ha.

Petani yang melakukan pengelolaan lahan dengan pola monokultur lebih memilih tanaman akasia (Acacia mangium). Jarak tanam yang digunakan petani untuk tanaman akasia (Acacia mangium) yaitu $3 \mathrm{~m} \mathrm{x} 3 \mathrm{~m}$. Dengan jarak tanaman tersebut untuk lahan seluas 1 ha petani dapat menanam pohon akasia sebanyak 1.111 batang. Petani berharap dengan jarak tanam tersebut jumlah kayu yang dihasilkan dapat maksimal. Hal ini didukung dengan penelitian yang dilakukan oleh (Siarudin, 2007) menyebutkan bahwa kayu akasia pada jarak tanam $3 \mathrm{~m}$ x $3 \mathrm{~m}$ memiliki diameter lebih baik dibandingkan dengan jarak tanam $2 \mathrm{~m} \times 3 \mathrm{~m}$. Hal ini dikarenakan jarak tanam cukup berpengaruh terhadap pertumbuhan diameter, yaitu jarak tanam yang lebar menghasilkan pertumbuhan diameter lebih besar.

Petani yang melakukan pengelolaan lahan dengan pola polikultur, petani menanam dua jenis tanaman kayu yaitu akasia (Acacia mangium) dan karet (Hevea brassiliensis). Sedangkan pada lahan yang dikelola dengan sistem agroforestri petani mengkombinasikan tanaman akasia (Acacia mangium) dengan perlebahan (Apis cerana) yaitu sebanyak 16 petani (40\%) pada lahan seluas 26 ha.

Pemilihan tanaman akasia (Acacia mangium) dilakukan karena tanaman tersebut dinilai sesuai dengan struktur tanah di lahan hutan rakyat yang merupakan tanah berbatu. Hal ini sejalan dengan hasil penelitian yang dilakukan oleh Lestari (2012) yang menyebutkan bahwa tanaman akasia (Acacia mangium) merupakan tanaman yang mampu tumbuh pada tanah berbatu, karena memiliki sistem perakaran yang dalam. Tanaman akasia (Acacia mangium) juga dapat dipanen pada umur 7-8 tahun. Selain itu alasan lain yang menyebabkan petani memilih tanaman akasia (Acacia mangium) adalah karena saat awal berdirinya hutan rakyat di Desa Buana Sakti tahun 2007, petani memperoleh bantuan bibit akasia (Acacia mangium) dari Dinas Kehutanan setempat sehingga petani tidak perlu mengeluarkan biaya untuk pembelian bibit, akan tetapi pada perkembangannya pengadaan bibit dilakukan oleh masyarakat sendiri.

Selain tanaman akasia (Acacia mangium), petani juga menanam tanaman karet (Hevea braziliensis). Alasan pemilihan tanaman karet (Hevea braziliensis) tersebut adalah karena karet (Hevea braziliensis) merupakan salah satu tanaman kehutanan yang memberikan sumbangan pendapatan bagi petani. Hasil non kayu dari tanaman karet dapat dipanen seminggu dua kali, sedangkan hasil kayunya akan dipanen ketika usia tanaman tersebut sudah tidak produktif lagi untuk menghasilkan getah yaitu pada usia 20-25 tahun jadi hasil kayu dari tanaman karet bagi petani di Desa Buana Sakti hanya dianggap sebagai hasil sampingan. Tanaman karet di Desa Buana Sakti saat ini sudah berusia produktif untuk menghasilkan getah yaitu berusia 5 atau 7 tahun, sehingga jumlah getah yang dihasilkan setiap bulannya cukup banyak.

Hutan rakyat di Desa Buana Sakti tidak dikelola dengan menggunakan sistem silvikultur intensif. Hal tersebut ditandakan dengan petani tidak melakukan penyemaian benih, penyulaman tanaman yang mati, dan pemangkasan cabang. Petani hutan rakyat di Desa Buana Sakti hanya melakukan pemupukan dan tidak melakukan pemangkasan cabang sebelum tanaman berusia 6 bulan. Berdasarkan penelitian yang dilakukan oleh Sudomo (2007) menyebutkan bahwa pemangkasan cabang pada akasia (Acacia mangium) sebaiknya dilakukan sebelum tanaman berumur 6 bulan agar diperoleh batang lurus tanpa cacat mata kayu serta agar tidak terjadi pertumbuhan menggarpu.

Keberadaan hutan rakyat di Desa Buana Sakti memberikan manfaat secara ekonomi bagi petani, hal ini dikarenakan penjualan hasil hutan rakyat, baik berupa kayu maupun non kayu dapat memberikan tambahan pendapatan. Pendapatan tersebut diperoleh dari pengurangan antara penerimaan dengan biaya yang telah dikeluarkan selama melakukan pengelolaan. 
Tanaman akasia (Acacia mangium) yang ditanam pada lahan hutan rakyat di Desa Buana Sakti sebagian besar baru berusia 4 tahun, sehingga untuk mengetahui pendapatan dari kayu, pendapatan dihitung dengan cara mengkonversikan setiap hasil yang diperoleh ke dalam bentuk nilai rupiah sesuai dengan harga jual produk di pasar lokal yang berlaku pada saat penelitian berlangsung. Dengan cara mengali-kan banyaknya pohon yang akan dipanen dengan harga setiap batangnya.

Rata-rata pendapatan petani dari hutan rakyat adalah sebesar Rp 29.056.432 per ha per tahun. Pendapatan tersebut berasal dari tanaman kayu akasia (Acacia mangium), kayu karet (Hevea brassiliensis) dan kayu jati (Tectona grandis). Selain tanaman kayu pendapatan tersebut juga bersumber dari hasil non kayu yaitu berupa getah karet, dan perlebahan serta dari tanaman pertanian. Pendapatan tersebut tergolong tinggi, hal ini didukung dengan penelitian yang dilakukan oleh Kusumedi (2009) yang menyebutkan bahwa pendapatan hutan rakyat di Desa Tirip Kabupaten Wonosobo hanya sebesar Rp 5.672.957 per ha per tahun. Pendapatan tersebut diperoleh dari pengelolaan lahan secara agroforestri sama halnya dengan sistem pengelolaan lahan yang dilakukan petani di lahan hutan rakyat Desa Buana Sakti petani juga menerapkan sistem pengelolaan lahan secara agroforestri.

Hasil penelitian menunjukan bahwa sistem pengelolaan lahan dengan pola agro-forestri memberikan kontribusi lebih besar terhadap rata-rata pendapatan total petani yaitu sebesar Rp 15.026.096 per ha per tahun dibandingkan dengan pola monokultur yaitu sebesar Rp 5.088.187 per ha per tahun dan pola polikultur yaitu sebesar Rp 9.056.445 per ha per tahun. Pengelolaan lahan hutan rakyat dengan pola agroforestri memberikan pendapatan yang lebih besar bagi petani, karena petani tidak hanya menanam jenis tanaman kayu, tetapi mengkombinasikan dengan perlebahan. Oleh karena itu penerapan sistem agroforestri dalam pengelolaan hutan rakyat perlu ditingkatkan agar potensi pendapatan yang dapat diperoleh petani meningkat.

Kombinasi antara tanaman kehutanan dengan budidaya lebah madu, hanya diterapkan oleh petani hutan rakyat yang berada di Dusun Sidomukti. Kombinasi hutan rakyat dengan budidaya lebah madu memberikan pendapatan tambahan bagi petani, dari 40 orang petani yang menjadi responden hanya 10 responden (25\%) yang mengkombinasikan hutan rakyat dengan budidaya lebah madu. Sistem budidaya lebah madu di Desa Buana Sakti dilakukan dengan menggunakan glodok dan stup. Glodok biasanya terbuat dari batang kelapa yang telah dimodifikasi menjadi berongga. Sedangkan stup merupakan sarang lebah berbentuk kotak. Glodok dan stup biasanya diletakan diantara batang pohon akasia (Acacia mangium). Glodok akan diisi oleh lebah madu yang nantinya membentuk sebuah koloni sedangkan setiap stup diisi oleh satu ekor ratu lebah yang nantinya juga akan membentuk sebuah koloni baru, koloni tersebut kemudian dapat dijual oleh petani dengan harga Rp 350.000 per koloni dan Rp 50.000 per glodok. Usaha penangkaran lebah madu yang dilakukan petani menghasilkan koloni rata-rata 3 koloni per bulan per petani. Rata-rata pendapatan dari usaha penangkaran lebah madu adalah Rp 357.125 per tahun.

Petani yang menerapkan sistem agroforestri dapat memperoleh pendapatan lebih besar dibandingkan petani yang hanya menanam tanaman kayu. Hal ini dikarenakan dengan menerapkan sistem agroforestri petani dapat memperoleh pendapatan setiap bulannya, dibandingkan jika petani hanya menerapkan sistem tanam monokultur. Sama halnya dengan hasil penelitian yang dilakukan oleh Hardjanto (2001) yang menyebutkan bahwa dengan adanya pola tanam agroforestri petani akan lebih intensif dalam mengelola lahannya, sehingga disamping tanaman berkayu yang hasilnya bisa dipetik beberapa tahun ke depan, petani juga dapat memperoleh hasil dari jenis tanaman agroforestri, sehingga pendapatan yang diperoleh akan lebih besar.

Besar kecilnya pendapatan petani yang bersumber dari hutan rakyat dipegaruhi oleh biaya yang dikeluarkan selama pengelolaan hutan rakyat. Biaya yang dikeluarkan dalam 
pengelolaan hutan rakyat ini tidak terlalu banyak. Pada tanaman kayu petani hanya mengeluarkan biaya untuk upah tenaga kerja sewaktu melakukan penanaman yaitu sebesar Rp 30.000,00 per orang per hari, untuk lahan seluas 1 ha biasanya petani membayar 10 orang pekerja untuk melakukan penanam dan membutuhkan waktu selama 3 hari. Biaya lain yang harus dikeluarkan oleh petani adalah biaya pemupukan. Pemupukan dilakukan sebanyak 3 kali dalam 1 tahun, dalam satu kali pemupukan untuk lahan seluas 1 ha diperlukan 3 kwintal pupuk, harga tiap kwintal pupuk adalah sebesar Rp 190.000,00 per kwintal. Untuk tanaman karet (Hevea braziliensis) petani harus mengeluarkan biaya untuk pembelian bibit harga bibit yang harus dikeluarkan adalah sebesar Rp 2000 per bibit. Petani juga mengeluarkan biaya untuk penanaman yaitu sebesar Rp 30.000 per orang dan untuk lahan 1 ha biasanya diperlukan pekerja sebanyak 10 orang dalam waktu 2 hari pengerjaan. Biaya lain yang harus dikeluarkan adalah biaya pemupukan, pemupukan biasanya di-lakukan sebanyak 4 kali dalam satu tahun, untuk lahan 1 ha diperlukan pupuk sebanyak 3 kwintal setiap kali pemupukan, harga tiap kwintal pupuk adalah sebesar Rp 215.000.

Pada saat pemanenan hasil hutan rakyat baik berupa kayu maupun non kayu petani memilih untuk memanen hasilnya sendiri atau dengan anggota keluarganya dengan alasan agar biaya yang dikeluarkan tidak terlalu banyak. Petani pada umumnya menjual pohon dalam bentuk pohon berdiri secara borongan karena petani beranggapan menjual pohon dalam bentuk tegakan akan lebih muda, biaya untuk melakukan pemanenan dan pengangkutan hasil biasanya ditanggung oleh pembeli sehingga petani hanya menerima pendapatan bersih tanpa harus mengeluarkan biaya untuk pemanenan. Pendapatan yang diterima petani tergantung dari besar kecilnya dia-meter kayu serta jenis kayu yang dijual. Biasanya yang menjadi alasan petani hutan rakyat melakukan pemanenan kayu adalah jika ada kebutuhan yang mendadak, misalnya untuk biaya sekolah atau biaya pernikahan anak.

Tingkat keberhasilan petani dalam mengelola lahan hutan rakyat dilihat dari besarnya pendapatan yang diperoleh dibandingkan dengan biaya yang telah dikeluarkan selama masa pengelolaan. Faktor lain yang mempengaruhi besar kecilnya pendapatan petani dari hutan rakyat adalah produktifitas lahan hutan rakyat tersebut. Pendapatan yang dipeoleh petani hutan rakyat di Desa Buana Sakti dari pengelolaan lahan hutan rakyat tergolong besar jika dibandingkan dengan biaya yang dikeluarkan oleh petani selama melakukan pengelolaan.

Selain memiliki lahan hutan rakyat sebagian besar petani memiliki lahan pertanian yang hasilnya dapat memberikan tambahan tehadap pendapatan total bagi petani. Luas rata-rata lahan pertanian responden adalah 0,4 ha. Lahan pertanian yang dimilik petani pada umumnya adalah sawah yang ditanami padi, yang memberikan hasil tidak terlalu banyak karena tergantung pada cuaca atau musim. Jika musim panas maka sawah rawa ini tidak akan memberikan hasil, hal ini disebabkan karena pengairan pada sawah rawa hanya berasal dari air hujan. Sawah rawa ini biasanya dipanen satu kali dalam setahun. Selain tanaman padi beberapa petani menanam tanaman singkong yang dapat dipanen sekali dalam setahun.

Pendapatan rata-rata petani dari pertanian adalah sebesar Rp 1.734 .875 per tahun. Pendapatan tersebut disumbang dari hasil padi dan singkong. Dalam melakukan pemanenan petani memanennya sendiri atau dengan dibantu oleh anggota keluarga.

Pendapatan lain yang dapat memberikan tambahan pendapatan bagi petani hutan rakyat adalah pendapatan yang bersumber dari hewan ternak yang dimiliki oleh petani. Pada umumnya sebagian besar petani memiliki hewan ternak. Pendapatan dari hewan ternak dapat memberikan tambahan terhadap pendapatan total petani hutan rakyat. Dalam melakukan pemeliharaan hewan ternak, petani tidak memerlukan biaya yang besar, petani hanya mengeluarkan biaya untuk pembuatan kandang, sedangkan untuk pakan ternak petani tidak perlu mengeluarkan biaya, karena biasanya petani mencari pakan ternak sendiri. Pendapatan dari hewan ternak milik petani hutan rakyat dapat dilihat dari jenis hewan ternak yang dimiliki, umur ternak, serta besar kecilnya ukuran hewan ternak. 
Pendapatan rata-rata petani yang berasal dari hewan ternak adalah sebesar Rp 2.006.250 per tahun. Pendapatan tersebut berasal dari hewan ternak berupa sapi, kambing dan ayam.

Berdasarkan jumlah petani yang menjadi responden (40 orang), 20 orang $(50 \%)$ diantaranya memiliki pekerjaan lain selain bekerja sebagai petani hutan rakyat. Pekerjaan lain yang dilakukan oleh petani hutan rakyat diantaranya adalah bekerja sebagai buruh bangunan yaitu sebanyak 6 orang (15\%), bekerja sebagai PNS sebanyak 2 orang (5\%), bekerja sebagai pedagang sebanyak 3 orang $(7,5 \%)$, bekerja sebagai pengrajin sebanyak 5 orang $(12,5 \%)$ dan 4 orang $(10 \%)$ menjadi kepala dusun di Desa Buana Sakti.

Pekerjaan-pekerjaan tersebut memberikan pendapatan rata-rata sebesar $\mathrm{Rp} 3.624 .000$ per tahun. Pendapatan dari pekerjaan lain yang dilakukan oleh petani tersebut dapat digunakan untuk memenuhi kebutuhan sehari-hari. Pendapatan total yang diperoleh petani hutan rakyat dari setiap jenis bidang usaha sangat bervariasi. Hal ini tergantung oleh banyaknya jenis pekerjaan yang dilakukan oleh petani hutan rakyat.

Pendapatan total rata-rata petani dari hutan rakyat, pertanian, hewan ternak, dan pekerjaan lain adalah sebesar Rp 24.984.774 per tahun. Hasil dari hutan rakyat baik kayu maupun non kayu memberikan kontribusi yang paling tinggi yaitu sebesar Rp 17.619.649 per tahun $(70,54 \%)$ dari rata-rata pendapatan total petani. Kontribusi hutan rakyat terhadap pendapatan petani tergolong tinggi. Hal ini didukung dengan penelitian yang dilakukan oleh Hardjanto (2001) yang menyebutkan bahwa kontribusi hutan rakyat terhadap pendapatan petani hanya sebesar $31,45 \%$. Tingginya pendapatan dari hutan rakyat dikarenakan kombinasi tanaman di berbagai komponen dalam pengelolaan hutan rakyat memberikan tambahan pendapatan bagi petani.

Besarnya pendapatan yang diperoleh dari lahan hutan rakyat menyebabkan sebagian besar petani menggantungkan hidupnya dari hasil hutan rakyat baik berupa kayu maupun nonkayu. Oleh karena itu kegiatan pengelolaan hutan rakyat dinilai sangat menguntungkan bagi sebagian besar petani. Bagi sebagian besar petani hutan rakyat, pengelolaan hutan rakyat memberikan kontribusi yang cukup besar dikarenakan dalam melakukan pengusahan lahan hutan rakyat, petani tidak perlu mengeluarkan biaya yang mahal karena petani melakukan perawatan sendiri.

Dalam melakukan pengelolaan lahan hutan rakyat, sebagian responden mengalami kesulitan yang mengakibatkan hasil yang diperoleh dari lahan hutan rakyat tidak maksimal. Kesulitan yang dialami responden tersebut disebabkan karena kurangnya pengetahuan petani dalam melakukan pengelolaan hutan rakyat. Kurangnya modal yang dimiliki oleh petani sehingga beberapa petani tidak mampu untuk melakukan perawatan secara intensif terhadap tanaman yang ditanam di lahan hutan rakyat misalnya untuk biaya pembelian pupuk dan pestisida sehingga petani tidak melakukan pemupukan secara intensif, hal tersebut dapat menyebabkan tanaman yang ditanam tidak dapat tumbuh dengan baik dan mudah terserang hama penyakit, sehingga tanaman yang ditanam tersebut cacat atau mati hal ini yang menyebabkan berkurangnya pendapatan yang diperoleh petani hutan rakyat. Selain pemupukan, pengetahuan petani yang rendah akan aspek-aspek pengelolaan hutan rakyat yang baik.

\section{SIMPULAN}

Berdasarkan hasil penelitian yang dilakukan dapat disimpulkan hutan rakyat memberikan kontribusi sebesar Rp 24.775.804/Ha/Tahun $(66,70 \%)$ dari rata-rata pendapatan total petani sebesar Rp 37.147.887/Tahun. Berdasarkan sistem pengelolaan yang dilakukan, pendapatan dari agroforestri memberikan kontribusi lebih besar yaitu sebesar Rp10.250.816/ Ha/Tahun $(41.37 \%)$ dari rata-rata pendapatan total petani. Pola monokultur memberikan kontribusi sebesar Rp 5.933.764/ Ha/Tahun (23.95\%) terhadap rata-rata pendapatan total petani dan pola 
polikultur memberikan kontribusi sebesar Rp 8591224/Ha/Tahun (34.68\%) terhadap rata-rata pendapatan total petani.

\section{DAFTAR PUSTAKA}

Arikunto, S. 2000. Manajemen Penelitian. Buku. Penerbit Rineka Cipta. Jakarta.

Departemen Kehutanan R.I. 2011. Statistik Kehutanan Indonesia. Badan Planologi Kehutanan. Jakarta.

Elmira, S. 2009. Identifikasi Dan Inventarisasi Pengelolaan Hutan Rakyat Di Kecamatan Biru Biru. Universitas Sumatera Utara. Medan.

Hardjanto. 2001. Kontribusi hutan rakyat terhadap pendapatan rumah tangga di Sub DAS Cimanuk Hulu. Jurnal Manajemen Hutan Tropika. Vol VII. No. 2: 47-61 (2001). Diakses tanggal 29 Februari 2012. www. Hardjanto_kontribusi_hutan. Pdf.

Lestari, F. 2012. Perbanyakan Tanaman Akasia (Acacia Sp) Melalui Teknik Invitro di Balai Besar Penelitian Bioteknologi dan Pemuliaan Tanaman Hutan. Yogyakarta.

Profil Desa Buana Sakti. 2011. Badan Pemberdayaan Masyarakat Desa Kabupaten Lampung Timur. Tidak dipublikasikan.

Saefudin. 2007. Kajian komposisi tanaman hkm dan kontribusinya terhadap pendapatan rumah tangga di Desa Sumber Agung, Kecamatan Kemiling, Bandar Lampung. Universitas Lampung, Lampung.

Siarudin, M. 2007. Karakteristik dan variasi sifat fisik kayu mangium (Acacia mangium Willd.) pada beberapa jarak tanam dan kedudukan aksial-radial. Jurnal Pemuliaan Tanaman Hutan Vol 1 No 1 Juli 2007.

Sugiono. 2009. Metode Penelitian Kuantitatif dan Kualitatif. Buku. Alfabeta. Bandung. 